\title{
LEVANTAMENTO DOS PRINCIPAIS FATORES QUE CONTRIBUEM PARA A EVASÃO ESCOLAR NO CURSO DE ADMINISTRAÇÃO DE UMA INSTITUIÇÃO PRIVADA DE ENSINO SUPERIOR
}

\section{ARTIGO ORIGINAL}

OLIVEIRA, Luiz Rogério Cordeiro de ${ }^{1}$

COSTA, Stella Regina Reis da ${ }^{2}$

OLIVEIRA, Luiz Rogério Cordeiro de. COSTA, Stella Regina Reis da. Levantamento dos principais fatores que contribuem para a evasão escolar no curso de Administração de uma instituição privada de ensino superior. Revista Científica Multidisciplinar Núcleo do Conhecimento. Ano 04, Ed. 12, Vol. 04, pp. 116-131. Dezembro de 2019. ISSN: 2448-0959, Link de acesso: https://www.nucleodoconhecimento.com.br/administracao/principais-fatores

\section{RESUMO}

A boa qualidade da educação superior torna-se fundamental ao crescimento e desenvolvimento de um país, pois são os centros universitários que formam os profissionais que irão atuar como líderes e gestores das instituições públicas e privadas, administrando os seus recursos e cuidando da saúde e educação das novas

\footnotetext{
${ }^{1}$ Mestre pelo Programa de Mestrado Profissional em Sistemas de Gestão pela UFF Universidade Federal Fluminense (2019); Pós-Graduação em Docência do Ensino Superior pela AVM - Universidade Cândido Mendes (2013); graduação em Administração de Empresas pela Universidade Estácio de Sá (2014), graduação em Ciências Econômicas pela Universidade Gama Filho (1996).

2 Doutorado em Engenharia Química pela Universidade Federal do Rio de Janeiro (1991); mestrado em Engenharia Química pela Universidade Federal do Rio de Janeiro (1981) e possui graduação em Engenharia Química pela Universidade Federal do Rio de Janeiro (1979).
} 
gerações. A evasão de alunos dos cursos de nível superior, que impacta a formação de todos os profissionais, pode ter origem em vários fatores, cabendo às instituições de ensino superior buscar a implementação de soluções em seus processos de ensino e aprendizagem. Neste sentido, esta pesquisa tem por objetivo realizar um levantamento dos fatores que contribuem para a evasão de alunos de um curso de Administração de uma instituição privada de ensino auxiliando na proposta de ações para a redução da evasão escolar buscando melhorar a qualidade do ensino para manter o aluno matriculado e ativo no curso superior. Utilizou-se os conceitos da escala SERVQUAL de satisfação/insatisfação e outras abordagens da literatura para construção de um questionário distribuído a alunos de um curso de uma instituição privada de ensino superior. Após a coleta do questionário de pesquisa procedeu-se a análise dos resultados. Conclui-se que é necessária a adoção de medidas que humanizem as instituições e foquem no aluno, aproximando-o pelo exercício do diálogo, de forma a contribuir para a mitigação da evasão dos discentes de cursos de nível superior.

Palavras-chave: SERVQUAL, qualidade de serviço de ensino, evasão escolar.

\section{INTRODUÇÃO}

A boa qualidade da educação superior torna-se fundamental ao crescimento e desenvolvimento de um país, pois são os centros universitários que formam os profissionais que irão atuar como líderes e gestores das instituições públicas e privadas, administrando os seus recursos e cuidando da saúde e educação das novas gerações. Segundo Mello, Dutra e Oliveira (2001), o ensino superior tem sido crescentemente reconhecido como uma indústria de serviços e, como um setor, deve empenhar seus esforços em identificar as expectativas e necessidades de seus principais clientes, que são os estudantes.

Direcionado à mente das pessoas, e, portanto, sendo classificado como um serviço de ações intangíveis, o serviço educacional é de entrega contínua, sendo de baixa customização mesmo proporcionando um alto contato pessoal (LOVELOCK; WRIGHT, 2001). Realizado por meio de uma parceria entre uma organização de 
serviço e seu cliente compete às instituições de educação superior investir na busca pela excelência, aprimorando um padrão de qualidade que supere as expectativas e necessidades do discente, oferecendo um serviço educacional superior que ultrapasse as avaliações originadas de exigências legais (PEREIRA, 2004).

Nota-se que esses elementos têm alto fator subjetivo ligado à pessoa que percebe o serviço. Na verdade, de acordo com Kilbourne et al. (2004) cada tipo de serviço poderá ter determinantes que são considerados mais importantes que outros, dependendo das características de ambiente ou tipo de atividade.

As operações envolvendo serviço são de difícil mensuração da qualidade por apresentarem a característica da intangibilidade. Com o propósito de solucionar este problema, Parasuraman, Zeithaml e Berry (1985) desenvolveram uma metodologia na qual há uma comparação entre as expectativas e as percepções chamado Escala SERVQUAL, que é um instrumento de mensuração da qualidade proveniente deste modelo que trabalha com a diferença de escores (gaps) em forma de um questionário. A escala (questionário) SERVQUAL possui duas seções: uma destinada ao mapeamento das expectativas do cliente em relação a um segmento de serviço e outra destinada ao mapeamento da percepção em relação a uma determinada empresa de serviço (FITZSIMMONS E FITZSIMMONS, 2000). A Escala SERVQUAL original utiliza 22 questões para mensurar as cinco dimensões de qualidade de serviços: confiabilidade, tangibilidade, segurança, empatia e responsabilidade.

O presente trabalho é importante para a educação superior na medida em que contribui com uma nova tomada de consciência e melhoria da operação interna das rotinas para aprimorar o relacionamento com os estudantes do curso de administração.

A pesquisa pretendeu contribuir para uma redução dos índices de evasão e consequente melhoria da qualidade do ensino dos alunos do curso de administração em uma universidade privada do estado do Rio de Janeiro, contribuindo com a melhoria dos serviços ao proporcionar maior satisfação e facilidades no processo de aprendizagem desses estudantes envolvidos a partir da coleta de respostas através 
de um questionário com perguntas baseadas na Escala SERVQUAL, relacionadas a vida acadêmica do aluno e que influenciam em sua satisfação e decisão em permanecer matriculado no curso de Administração de Instituição Privada de Ensino Superior .

\section{FUNDAMENTAÇÃO TEÓRICA}

\subsection{A ESCALA SERVQUAL E A QUALIDADE DOS SERVIÇOS}

De acordo com Parasuraman, Zeithaml e Berry (1985), independente do tipo de serviço, os consumidores utilizam basicamente os mesmos critérios para avaliar sua qualidade. A qualidade do serviço passa a ser uma opinião geral do cliente a respeito da sua entrega, que é constituída por uma série de experiências bem ou malsucedidas. Medir e gerenciar as lacunas no serviço ajudará a empresa a melhorar sua qualidade. Mas não são apenas por meio dos gaps ou lacunas que os clientes avaliam um serviço, pode-se utilizar também as cinco dimensões amplas como critérios de julgamento como: confiabilidade, tangibilidade, responsabilidade, segurança e empatia.

\subsection{CONHECIMENTO ORGANIZACIONAL E EVASÃO}

O conhecimento organizacional pode ser considerado a capacidade de unificar o conhecimento tácito (prática, expertise, know how, valores etc) e o conhecimento explícito (manuais, livros, estudos etc) para alcançar a melhoria nos processos ou reposicionamento estratégico desses, através da inovação em tecnologia de processos. Portanto, não há maior importância entre os tipos de conhecimento, seja ele tácito ou explicito, apenas a interação entre eles que permite o conhecimento fluir, criando a espiral do conhecimento decorrente de quatro processos: socialização, externalização, combinação e internalização para auxiliar no combate a evasão escolar (PAIVA; SOUZA, 2009).

Segundo Takeuchi e Nonaka (2008), a partir da inteiração entre indivíduos se forma o ambiente de socialização entre alunos. Nesses espaços o conhecimento tácito é 
transmitido a partir do relacionamento entre os indivíduos, sendo passado por meio da observação do método realizado, da imitação e da execução de tarefas ou atividades em classe, ou seja, por intermédio de treinamento on the job (BENEVIDES, 2010). No entanto, é fundamental para se obter socialização a confiança mútua entre a equipe de instrutores e instruídos, pois a confiança está ligada à ação de compartilhar, dizendo respeito ao recebimento de algo em troca. Para a organização a confiança exerce uma influência motivante sobre os entrevistados, levando-os a compartilhar informações valiosas (SANTOS; SANTOS; BELUZZO, 2016).

Já o ambiente de Internalização é formado pela passagem do conhecimento explícito para o tácito. Para transformar em tácito, as melhores práticas indicadas são os manuais e propostas pedagógicas, apresentações do conhecimento técnico (relatos orais), apresentação de resultados com análise no modelo de lições aprendidas, para que facilite a internalização do conhecimento.

Segundo Takeuchi e Nonaka (2008), para o ambiente de combinação, que é a integração de conhecimento explícito para explícito, pode ocorrer através na troca de documentos, reuniões, treinamentos e educação formal.

Destarte isso, há outros momentos de aprendizagem que ocorrem, sobretudo, em ambientes empresariais de maneira informal, espontâneo através das interações e troca de experiências e essas interações são quase desconsideradas no processo de aprendizado. Entretanto, o processo de ensino-aprendizagem formalizado, concebido apenas pelo modelo unidirecional, onde de um lado está a fonte transmissora do saber (universidades, professores, as referências escritas no papel, vídeos, áudios etc) e do outro está a fonte receptora (discentes e colaboradores) apresenta significativas limitações, visto que neste modelo quase não há espaço para a maioria das trocas de ideias e interações estratégicas como as reflexões, análises e discussões importantes que deixaram de existir, permitindo-se notar que grande parte do que poderia ser transformado em conhecimentos válidos para a organização se perdeu com o tempo (SILVA, 2016). 


\section{MATERIAL E MÉTODO}

A amostra da pesquisa foi todos os alunos do curso noturno de administração de uma universidade privada do interior do estado do Rio de Janeiro, realizou-se uma pesquisa de campo, inicialmente com 10 alunos que responderam ao pré-teste. Após os devidos ajustes, 255 estudantes, responderam ao questionário de pesquisa com 15 perguntas fechadas e 06 opções de respostas cobrindo todo o curso de administração da modalidade presencial, do turno da noite. O desenvolvimento da pesquisa procurou refletir as expectativas, anseios e necessidades dos alunos em sala de aula. Os enunciados e as opções de respostas, tentaram descobrir os níveis de aproximação e segurança dos alunos com os conteúdos apresentados pelos professores em classe.

Buscou-se identificar as percepções predominantes sobre a qualidade dos serviços da instituição que, de acordo com a literatura podem frustrar, igualar ou até mesmo superar as expectativas dos alunos.

Com base em Parasuraman, Zeithaml e Berry (1985); e Lourenço, e Knop (2011), o instrumento utilizado tinha 15 perguntas impressas e foram entregues aos estudantes no mês de fevereiro de 2018 e recolhidos ao final de cada aula.

\section{RESULTADOS E DISCUSSÕES}

Dos 255 alunos participantes da pesquisa, $40 \%$ ou 102 alunos são do sexo masculino, com idade variando de 22 e 49 anos. Desses, $73 \%$ ou 74 alunos trabalham formalmente (empresário ou microempreendedor individual ou empresário, vínculo empregatício, estágio e trabalho de jovem aprendiz), enquanto $27 \%$ não trabalham, estão desempregados ou em busca de oportunidades profissionais.

O público feminino representou-se por 153 alunas ou $60 \%$ do total pesquisado, com idade variando entre 19 e 42 anos. Aproximadamente 67\% alunas trabalham formalmente, enquanto $33 \%$ são donas de casa, mas que estão em busca das 
primeiras oportunidades ou pretendem retornar ao mercado de trabalho formal quando as oportunidades surgirem.

Figura 1 - Perfil do público abordado

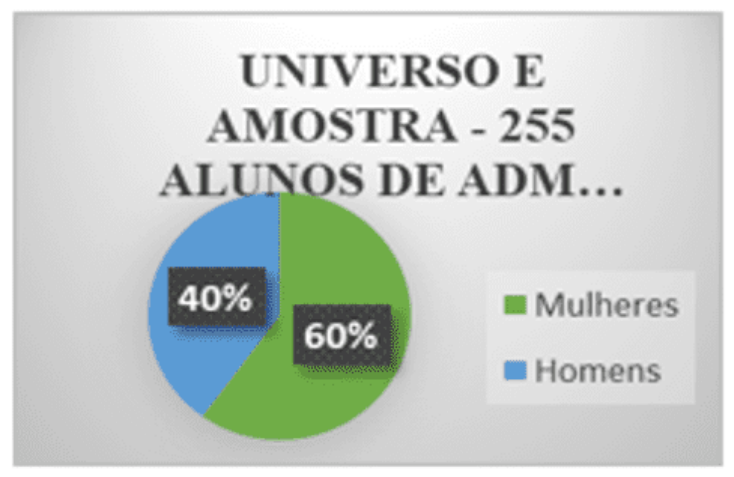

\section{ALUNOS CURSO DE ADM INSTITUIÇÃO PRIVADA HOMENS}

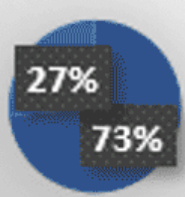

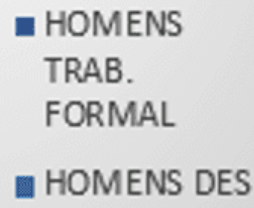

ALUNOS CURSO DE ADM INSTITUIÇÃO PRIVADA MULHERES

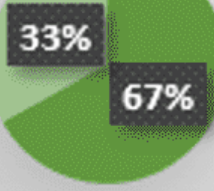
- MULHERES
TRAB
FORMAL

Fonte: Dados da Pesquisa

A categorização de respostas considerou a opção indicada pela letra $A$ equivalente a muito bom, $B$ representava bom, $C$ regular, $D$ ruim, $E$ muito ruim e $F$ como não se aplica. Os resultados consolidados estão no quadro 1.

Quadro 1 - Distribuição de frequência da qualidade percebida

\begin{tabular}{|c|c|c|c|c|c|c|c|}
\hline ATRIBUTOS & PERGUNTAS & A & B & C & D & E & $\mathbf{F}$ \\
\hline TANGIBILIDADE & $\begin{array}{l}\text { 1) As instalações } \\
\text { físicas são } \\
\text { adequadas } \\
\text { (adequadas, }\end{array}$ & $24 \%$ & $48 \%$ & $23 \%$ & $3 \%$ & $1 \%$ & $1 \%$ \\
\hline
\end{tabular}




\begin{tabular}{|c|c|c|c|c|c|c|c|}
\hline & $\begin{array}{l}\text { arejadas } \\
\text { iluminadas)? }\end{array}$ & & & & & & \\
\hline TANGIBILIDADE & $\begin{array}{l}\text { 2) O acervo da } \\
\text { biblioteca } \\
\text { compatível com as } \\
\text { exigências do } \\
\text { curso? }\end{array}$ & $21 \%$ & $46 \%$ & $22 \%$ & $3 \%$ & $1 \%$ & $5 \%$ \\
\hline TANGIBILIDADE & $\begin{array}{l}\text { 3) Possui } \\
\text { laboratório de } \\
\text { informática } \\
\text { adequado } \\
\text { (quantidade e } \\
\text { características dos } \\
\text { equipamentos)? }\end{array}$ & $25 \%$ & $47 \%$ & $23 \%$ & $4 \%$ & $1 \%$ & $1 \%$ \\
\hline CONFIABILIDADE & $\begin{array}{l}\text { 4) O curso de } \\
\text { administração } \\
\text { promoveu palestras } \\
\text { de acadêmicos e } \\
\text { executivos? }\end{array}$ & $19 \%$ & $44 \%$ & $21 \%$ & $5 \%$ & $3 \%$ & $8 \%$ \\
\hline CONFIABILIDADE & $\begin{array}{l}\text { 5)O curso de } \\
\text { administração } \\
\text { promoveu cursos } \\
\text { de extensão? }\end{array}$ & $15 \%$ & $38 \%$ & $26 \%$ & $10 \%$ & $3 \%$ & $8 \%$ \\
\hline CONFIABILIDADE & $\begin{array}{l}\text { 6) As disciplinas } \\
\text { são relevantes para } \\
\text { a capacitação } \\
\text { profissional? }\end{array}$ & $30 \%$ & $49 \%$ & $18 \%$ & $1 \%$ & $1 \%$ & $1 \%$ \\
\hline PRESTEZA & $\begin{array}{l}\text { 7) A instituição } \\
\text { mantém os alunos } \\
\text { informados sobre o } \\
\text { curso? }\end{array}$ & $18 \%$ & $25 \%$ & $22 \%$ & $16 \%$ & $10 \%$ & $9 \%$ \\
\hline
\end{tabular}




\begin{tabular}{|c|c|c|c|c|c|c|c|}
\hline PRESTEZA & $\begin{array}{l}\text { 8) O atendimento } \\
\text { prestado pelos } \\
\text { funcionários } \\
\text { secretária } \\
\text { adequando? }\end{array}$ & $18 \%$ & $26 \%$ & $17 \%$ & $19 \%$ & $12 \%$ & $8 \%$ \\
\hline PRESTEZA & $\begin{array}{l}\text { 9) A coordenação } \\
\text { está sempre } \\
\text { disponível para } \\
\text { atender o aluno? }\end{array}$ & $18 \%$ & $32 \%$ & $25 \%$ & $13 \%$ & $10 \%$ & $2 \%$ \\
\hline SEGURANÇA & $\begin{array}{l}\text { 10) A instituição } \\
\text { fornece elementos } \\
\text { de comunicação } \\
\text { (murais, manuais, } \\
\text { avisos, e-mails) que } \\
\text { mantêm os alunos } \\
\text { informados? }\end{array}$ & $23 \%$ & $39 \%$ & $26 \%$ & $9 \%$ & $2 \%$ & $1 \%$ \\
\hline SEGURANÇA & $\begin{array}{l}\text { 11) A exposição } \\
\text { das aulas favorece } \\
\text { a segurança do } \\
\text { aprendizado? }\end{array}$ & $15 \%$ & $57 \%$ & $25 \%$ & $1 \%$ & $1 \%$ & $1 \%$ \\
\hline SEGURANÇA & $\begin{array}{l}\text { 12) Os professores } \\
\text { e colaboradores } \\
\text { são } \\
\text { corteses compre } \\
\text { alunos? }\end{array}$ & $33 \%$ & $45 \%$ & $19 \%$ & $2 \%$ & $1 \%$ & 0 \\
\hline EMPATIA & $\begin{array}{l}\text { 13) A universidade } \\
\text { compreende as } \\
\text { necessidades } \\
\text { específicas dos } \\
\text { alunos? }\end{array}$ & $14 \%$ & $37 \%$ & $22 \%$ & $13 \%$ & $3 \%$ & $11 \%$ \\
\hline
\end{tabular}




\begin{tabular}{|l|l|l|l|l|l|l|l|}
\hline EMPATIA & $\begin{array}{l}\text { 14) Os professores } \\
\text { dãor atenção } \\
\text { individualizada aos } \\
\text { alunos? }\end{array}$ & $18 \%$ & $44 \%$ & $30 \%$ & $5 \%$ & $1 \%$ & $2 \%$ \\
\hline EMPATIA & $\begin{array}{l}15) \text { Os professores } \\
\text { entendem as reais } \\
\text { necessidades dos } \\
\text { alunos? }\end{array}$ & $36 \%$ & $46 \%$ & $14 \%$ & $3 \%$ & $1 \%$ & 0 \\
\hline QUALIDADE GERAL DO CURSO & $21 \%$ & $42 \%$ & $23 \%$ & $7 \%$ & $3 \%$ & $4 \%$ \\
\hline
\end{tabular}

Fonte: Dados da Pesquisa

Analisando os questionários de pesquisa dos 255 alunos pesquisados, percebeu-se que na primeira questão (FIGURA 2): as instalações físicas são adequadas (bem cuidadas, arejadas e iluminadas)?

Figura 2 - Análise das respostas à Questão 1

\section{Questão 1}

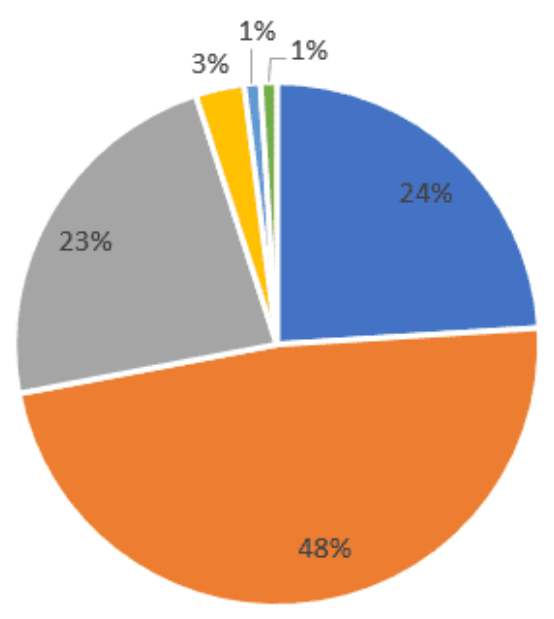

- $A=B=C=D=E-F$

Fonte: Dados da Pesquisa 
Na segunda pergunta: o acervo da biblioteca é compatível com as exigências do curso? e na terceira questão: a sua universidade disponibiliza laboratórios de informática com equipamentos adequados e suficientes para a aprendizagem dos conteúdos propostos? Respectivamente observou-se o seguinte resultado (FIGURA 3):

Figura 3 - Análise das respostas às Questões 2 e 3

\section{Questão 2}

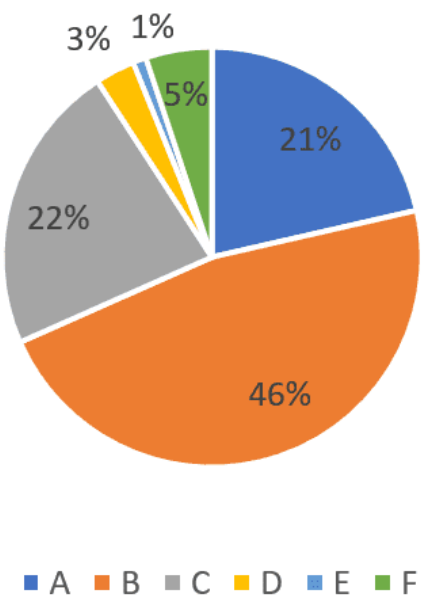

Questão 3

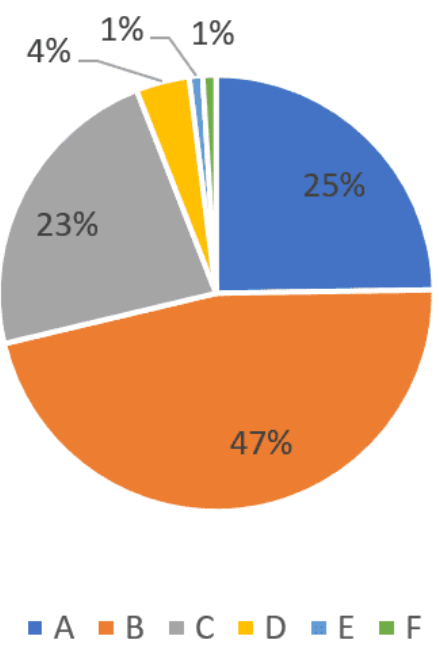

Fonte: Dados da Pesquisa

Corroborando com o que foi abordado por Leite, Fernandes e Broilo (2012), a avaliação geral dos resultados demostrou a importância da proposta de fornecer instrumentos que encorajem os alunos a refletir, de forma crítica e madura sobre os conteúdos ministrados tanto em sala de aula como nos laboratórios da instituição.

A questão quatro: o curso de administração promoveu palestras de acadêmicos e executivos? A pergunta cinco: o curso de administração promoveu cursos de extensão? e a questão seis: como você percebe os conteúdos das disciplinas em relação a sua futura profissão? Refletiram uma boa avaliação no que diz respeito a palestras, cursos de extensão e relevância de conteúdo das disciplinas e a profissão do administrador (FIGURAS 4). 
Figura 4 - Análise das respostas às Questões 4, 5 e 6

\section{Questão 4}

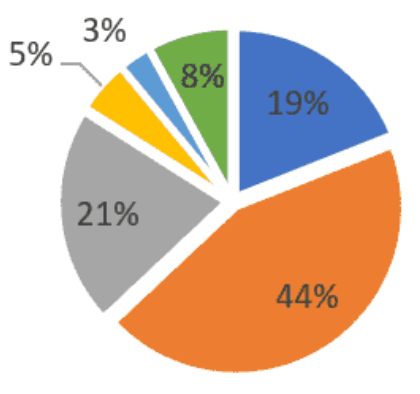

$\because A \backsim B \backsim C \backsim D \backsim E \backsim F$

\section{Questão 5}

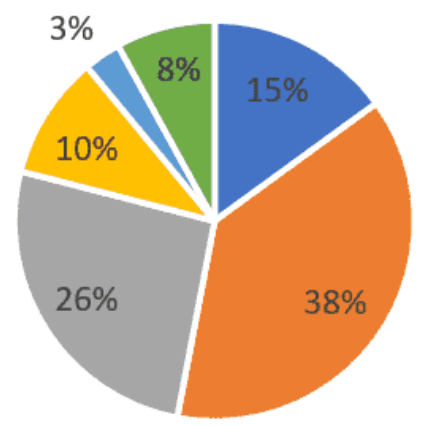

$\because A=B \backsim C \backsim D \backsim E \backsim F$

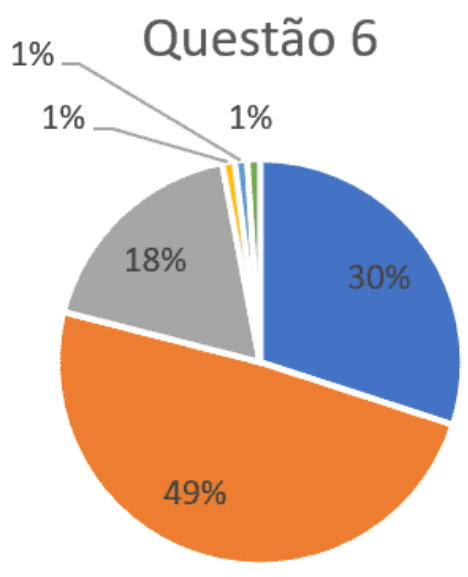

Fonte: Dados da Pesquisa

De acordo com a literatura a partir de Parasuraman, Zeithaml e Berry (1985); e Lourenço e Knop (2011), as ações devem ser convergentes, isto é, todos os elos departamentais da universidade devem agir com coerência, transparência e bom senso para que não haja gaps ou ruídos em nenhum processo, como forma de evitar insatisfações, desânimos e futuras evasões desses estudantes.

A sétima questão: a instituição se comunica de forma eficaz com todos os alunos sobre tudo o que acontece no curso de administração? Apresentou um certo equilíbrio 
nas respostas, que avaliavam como boa e como regular a forma de comunicação com a universidade, o que constitui um importante ponto de atenção a ser observado pela gestão e por todos os outros funcionários da instituição (FIGURA 5).

Figura 5 - Análise das respostas à Questão 7

\section{Questão 7}

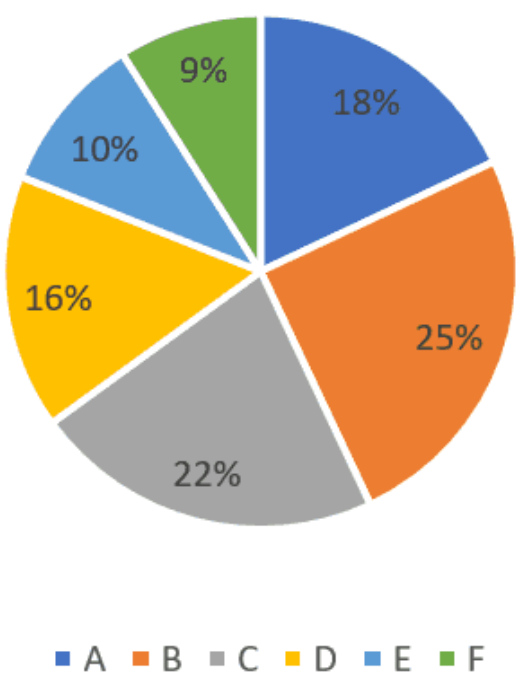

Fonte: Dados da Pesquisa

Nas questões oito: o atendimento prestado pelos funcionários da secretaria é adequando? E nove: a coordenação está sempre disponível para atender o aluno? Apurou-se (FIGURA 6): 
Figura 6 - Análise das respostas às Questões 8 e 9

\section{Questão 8}

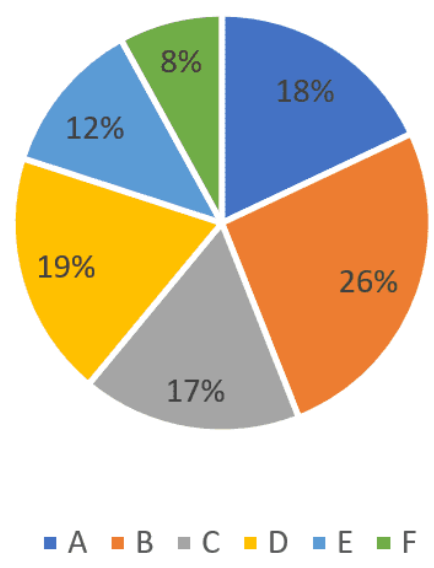

\section{Questão 9}

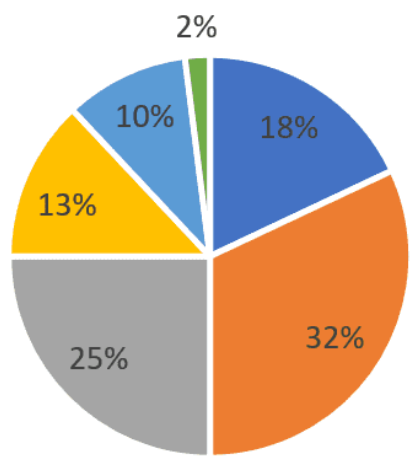

$\because A-B=C \backsim D=E \backsim F$

Fonte: Dados da Pesquisa

Nas questões oito e nove, percebeu-se uma insatisfação de 30 alunos ou 12\% e 26 estudantes ou 10\%, respectivamente, na escolha da opção muito ruim para o atendimento do pessoal de secretaria. Esse diagnóstico requer uma atenção especial às rotinas do pessoal da secretaria e do coordenador de curso como forma de viabilizar meios para ouvir os alunos, sanando suas necessidades imediatas.

Nas questões dez: A instituição fornece elementos de comunicação (murais, manuais, avisos, e-mails) que mantêm os alunos informados? Onze: a exposição das aulas favorece a segurança do aprendizado? E na pergunta doze: os professores e colaboradores são sempre corteses com os alunos? Quando comparada com outros padrões de respostas, nota-se uma boa avaliação em destaque com tendência para muito bom (FIGURA 7). 
Figura 7 - Análise das respostas às Questões 10, 11 e 12

\section{Questão 10}

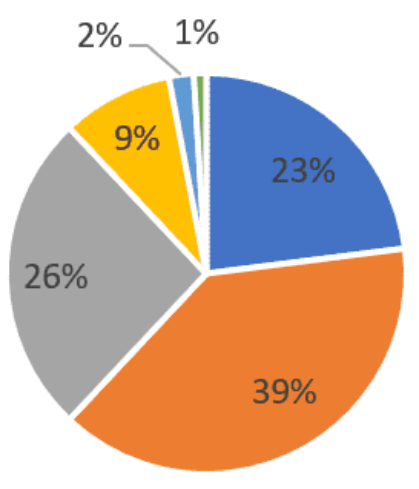

$\because A \backsim B \backsim C \backsim D \backsim E \backsim F$

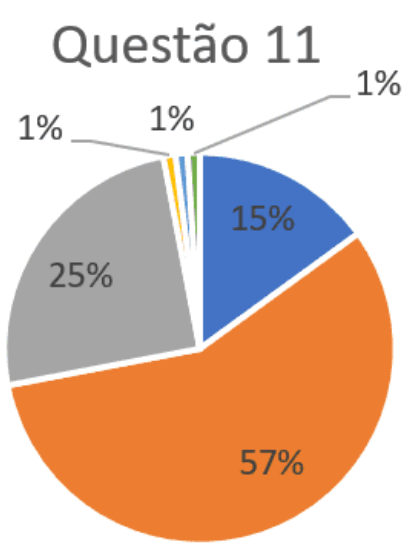

$\because A \backsim B \backsim C \backsim D \| E \backsim F$

\section{Questão 12}

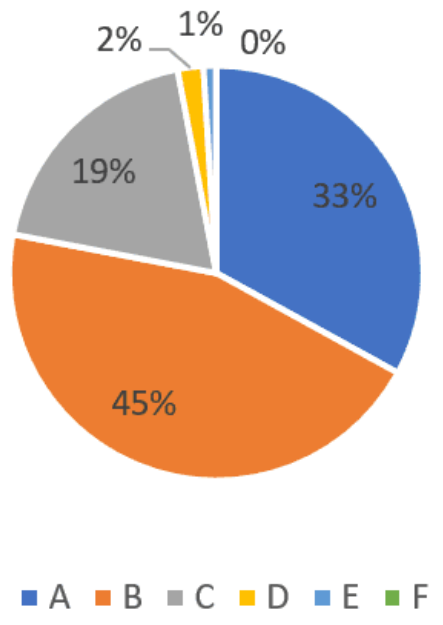

Fonte: Dados da Pesquisa

Todavia, há que se considerar um ponto de atenção favorável à dinâmica operacional da instituição de ensino, em especial nessa questão, onde percebeu-se uma melhora da satisfação dos serviços prestados no item a (muito bom), obtendo-se $O$ que equivale a $33 \%$ do total dos estudantes em comparação com outros itens da mesma pergunta. 
Nas questões 13: a universidade possui e disponibiliza outros recursos humanos e tecnológicos para auxiliar os alunos que têm dificuldades no aprendizado dos conteúdos fora da sala de aula? Pergunta 14: os professores dão atenção individualizada aos alunos? E 15: os professores têm sensibilidade e boa vontade permanente para sanar as dúvidas e necessidades dos alunos em sala de aula? Quando comparada com outros padrões de respostas, nota-se uma boa avaliação (FIGURA 8)

Figura 8 - Análise das respostas às Questões 13, 14 e 15

\section{Questão13}

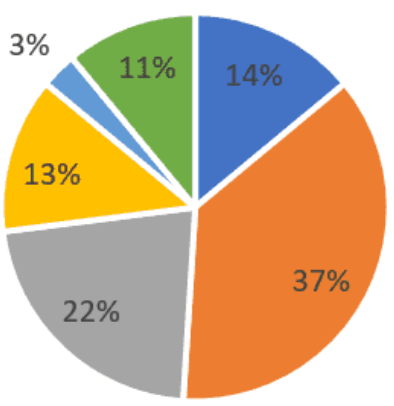

$-A=B=C=D=E-F$

\section{Questão 14}

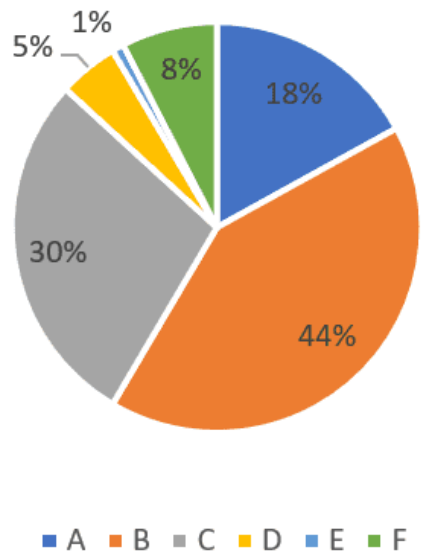

\section{Questão 15}

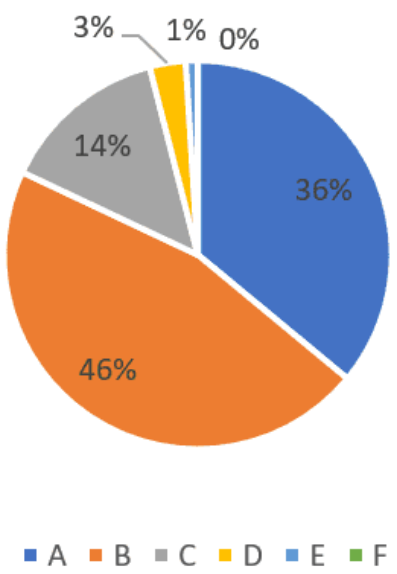

Fonte: Dados da Pesquisa 
Outros trabalhos, assim como o de Tureta, Rosa, e Oliveira (2007) evidenciam a baixa percepção de qualidade no que se refere ao conteúdo das disciplinas.

Com base na pesquisa realizada, percebeu-se que os sistemas e recursos em geral precisam se adequar às necessidades dos estudantes em horários e com meios que possa favorecer o processo de ensino e aprendizagem dos mesmos, em períodos compatíveis com suas demandas individuais, com ambiente limpo, organizado, bem sinalizado e com rápido e eficiente acesso à internet disponível para todos os estudantes, exceto em períodos de avaliações on-line, onde a totalidade dos laboratórios da instituição estão comprometidos com as avaliações de todos os cursos.

A comunicação é sempre um fator crítico de sucesso ou insucesso e carece de atenção especial em qualquer relação estabelecida entre a instituição de educação superior e o aluno da graduação. De acordo com os padrões de respostas da amostra, percebe-se que as comunicações precisam ser melhor desenvolvidas por parte de todos os funcionários da instituição.

Os resultados apontaram que $63 \%$ dos 255 entrevistados consideraram para as 15 questões respostas $\mathrm{A}$ ou $\mathrm{B}$, respectivamente muito boa (21\%) e boa (42\%) na avaliação da qualidade geral do curso.

Figura 9 - Qualidade geral do curso

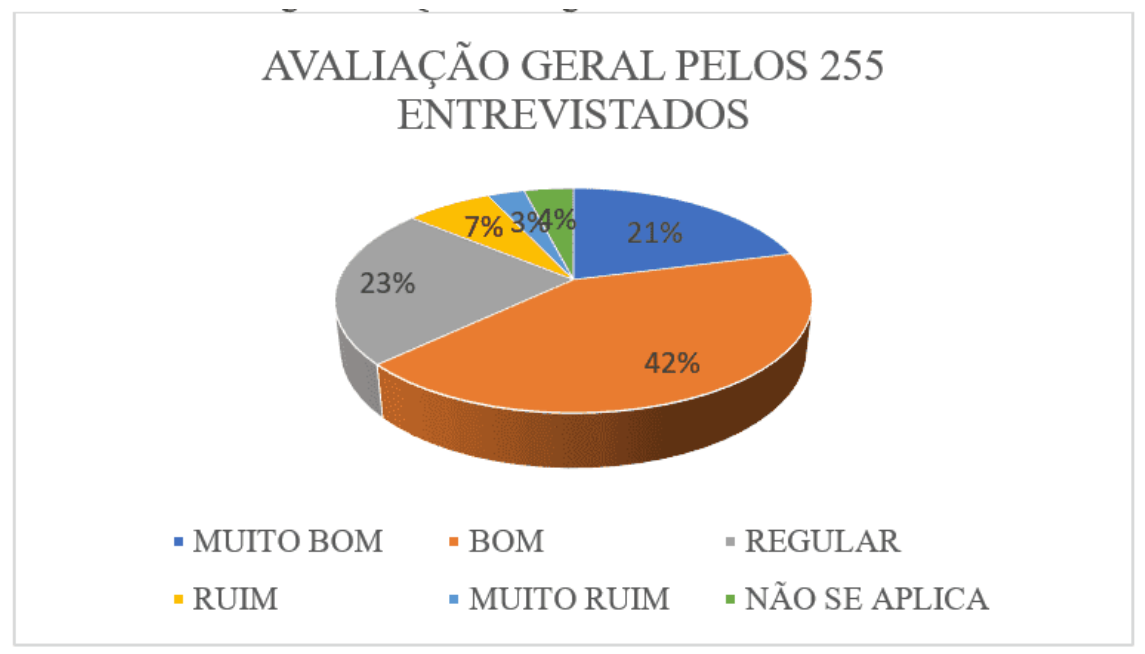


Fonte: Dados da Pesquisa

O ensino superior caracteriza-se pela complexidade e pelos resultados a longo prazo, e qualquer análise que o vislumbre é sempre pontuada por controvérsias segundo Mello, Dutra e Oliveira (2001). Devido à importância social de que desfruta, qualquer mudança na estrutura de sua oferta, em particular quando referente ao ensino superior público, é motivo para ampla discussão. No ensino particular, em razão das suas próprias características de mercado, esse processo se acentua.

Uma polêmica que há muito ronda o tema diz respeito a necessidade de adaptação das IES às exigências de mercado. Abordagens divergentes podem produzir visões tão distantes quanto aquela que vê estritamente o foco social deste tipo de organização e aquela que a define como tendo fins lucrativos e de rentabilidade (TOMASSI; AQUIN; CARVALHO, 2008).

Não é uma saída adequada considerar as necessidades e problemas dos alunos, bem como as imediatas soluções, com demora na apresentação de resposta, passando a criação de uma série de paliativos objetivando não deixar clara a incapacidade momentânea de apresentar soluções e esconder algumas limitações para a tomada de decisão. Tão pouco manter a "crença" de que sendo sinceros com o aluno, ele irá ficar chateado se a resposta da demanda for negativa e, simplesmente se recusará a permanecer na instituição. Muitas vezes, uma boa saída é compartilhar o problema com o aluno, dialogando com ele. A sinceridade precisa ser a regra e acima de tudo deve-se pensar primeiro naquilo que é melhor para o seu aluno e depois naquilo que porventura poderá agradá-lo.

Neste sentido é recomendável aperfeiçoar a medição dos índices de satisfação e insatisfação, com ferramentas como a utilizada nesta pesquisa, a escala servqual, reduzindo o tempo para esta análise, direcionando o foco para o aluno com respostas mais ágeis e decisões acertadas por parte da coordenação de curso e gestão do campus, pois todo projeto sólido de educação deve contemplar a permanente inovação e qualidade do serviço oferecido ao estudante. Essas medidas devem ser 
viáveis sob o ponto de vista das propostas de ensino e flexível financeiramente para manter o estudante na instituição, evitando-se a evasão do mesmo.

\section{CONCLUSÃO}

Através do questionário de pesquisa aplicado para todos os alunos, os fatores com maiores criticidades e que mais se destacaram na decisão de evadir do curso de administração foram: Ineficiência do processo motivacional (programação cultural ou jogos, dinâmicas, simulações e treinamentos relacionados ao mercado de trabalho), ausência de aulas práticas (como por exemplo implementando visitas técnicas à grandes empresas da região, seminário e congressos fora do campus universitário) e dificuldades em adaptar-se à cultura acadêmica.

Com base nas respostas obtidas pela pesquisa realizada em todas as salas de aula do curso de Administração de uma instituição privada de ensino superoir, verificou-se que o setor de secretaria representa o "cartão de visita" da instituição e precisa de atenção especial, exigindo-se maiores capacitações e implantação de métodos alternativos para agilizar as rotinas, melhorar 0 atendimento ao aluno para a resolução de seus problemas.

Entretanto, outras áreas também precisam se ajustar às demandas dos alunos como a biblioteca com a permanente atualização do acervo, os laboratórios de informática com todos os equipamentos funcionando e com permanente manutenção preventiva e melhor sinal de internet para atender a comunidade acadêmica em suas pesquisas.

Com o objetivo de reduzir o número de evasões, uma instituição privada de ensino superior precisa perceber que ao se humanizar e focar no aluno, entendendo o seu real papel de agente transformador, de instrução e formação, e, ao se aproximar do aluno, exercita e aprofunda o diálogo, a tolerância e a compreensão, o que naturalmente contribui para a motivação em aceitar as propostas acadêmicas e melhoria da relação aluno-universidade. Para tal, a adoção de um método de avaliação que leve em consideração as 5 dimensões mais relevantes na prestação de serviços de qualidade torna-se essencial. 


\section{REFERÊNCIAS}

BENEVIDES, V. L. A. Os estilos de liderança e as principais táticas de influência utilizadas pelos líderes brasileiros. Rio de Janeiro, 2010. Dissertação (Mestrado Executivo em Gestão Empresarial) - EBAPE Centro de Formação Acadêmica e de Pesquisa, Escola brasileira de administração pública e de empresas, Fundação Getúlio Vargas - FGV, Rio de Janeiro, 2010.

FITZSIMMONS, J. A.; FITZSIMMONS, N. J. Administração de serviços: operações, estratégias e tecnologia de informação. Porto Alegre: Bookman, 2000.

KILBOURNE, W. E; DUFFY, J.; DUFFY, M.; GIARCHI, G. The applicability of SERVQUAL in crossnational measurements of health-care quality. Journal of Services Marketing, v. 18, n. 7, 2004, p. 524-533.

LOURENÇO, C. D. S.; KNOP, M. F. T. Ensino Superior em Administração e Percepção da Qualidade de Serviços: uma aplicação da escala SERVIQUAL. São Paulo. 2011.

LEITE, D. (org) FERNANDES, C. B.; BROILO, C. L. (colab). Qualidade da educação superior: avaliação e implicações para o futuro da universidade. Porto Alegre: EDIPUCRS, 2012. Disponível em: http://www.ufrgs.br/inov/docs/qualida de-daeducacao-superior-aval-eimplic-p-o-futuro-da-univ Acesso em: 25 set 2019.

LOVELOCK, C.; WRIGTH, L. Serviços: marketing e gestão. São Paulo: Saraiva, 2001.

MELLO, S. C. B.; DUTRA, H. F. O.; OLIVEIRA, P. A. S. Avaliando a qualidade de serviços educacionais numa IES: o impacto da qualidade percebida na apreciação do aluno de graduação. Revista O\&S, v. 8, n.21, Maio/Agosto, 2001, p. 125-137.

PAIVA, S. B.; SOUZA, B. S. P. Compartilhamento do conhecimento no ambiente acadêmico: uma análise a partir da percepção de docentes universitários. Qualitas Revista Eletrônica, Vol.8. № 3 (2009). Universidade Estadual da Paraíba, UEPB. 2009. 
<http://revista.uepb.edu.br/index.php/qualitas/article/view/635/341> Acesso em: 03 de set. de 2019.

PARASURAMAN, A.; ZEITHAML, V.; BERRY, L. L. SERVQUAL, A multiple item scale for measuring Perceptions of Service Quality. Journal of Retailing, vol. 64 No. 1, P 1240, 1985.

PEREIRA, C. Evolução qualitativa na educação superior. In: OLIVEIRA, O. J. (org.). Gestão da qualidade: tópicos avançados. São Paulo: Thonsom Learning, 2004.

SANTOS, V. C. B.; SANTOS, C. A.; BELUZZO, R. C. B.; A competência em informação em articulação com a inteligência competitiva no apoio ao alinhamento estratégico das informações nas organizações. Perspectivas em Gestão \& Conhecimento, João Pessoa, v. 6, Número Especial, p. 45-60, jan. 2016.

SILVA, M. M. A gestão do conhecimento e a aprendizagem organizacional: contribuições para o processo de mudança e expansão em uma instituição de ensino superior do Paraná. Maringá, 2016. Dissertação (Mestrado em Gestão do Conhecimento nas Organizações) - Programa de Pós-Graduação Lato Sensu em Gestão do Conhecimento nas Organizações da Unicesumar - Centro Universitário Cesumar. Maringá, $2016 . \quad$ Disponível em: $<$ https://www.unicesumar.edu.br/presencial/wpcontent/uploads/sites/2/2018/05/MARA-MICHELA-DA-SILVA.pdf>Acesso em: 01 out. 2019.

TAKEUCHI, H.; NONAKA, I. Gestão do Conhecimento. Bookman, Porto Alegre, 2008. p. 17-38.

TURETA, C; ROSA, A. R.; OLIVEIRA, V. C. S. Avaliação crítica de serviços educacionais: o emprego do modelo SERVQUAL. REGE: Revista de Gestão, São Paulo, v. 14, n. 4, p. 33-45. 2007.

Enviado: Novembro, 2019. 
Aprovado: Dezembro, 2019. 